\title{
Synthesis, Characterization, and Antimicrobial Activity of Copper Oxide Nanoparticles
}

\author{
Maqusood Ahamed, ${ }^{1}$ Hisham A. Alhadlaq, ${ }^{1,2}$ M. A. Majeed Khan, ${ }^{1}$ \\ Ponmurugan Karuppiah, ${ }^{3}$ and Naif A. Al-Dhabi ${ }^{3}$ \\ ${ }^{1}$ King Abdullah Institute for Nanotechnology, King Saud University, P.O. Box 2454, Riyadh 11451, Saudi Arabia \\ ${ }^{2}$ Department of Physics and Astronomy, King Saud University, Riyadh 11451, Saudi Arabia \\ ${ }^{3}$ Department of Botany and Microbiology, College of Science, King Saud University, Riyadh 11451, Saudi Arabia
}

Correspondence should be addressed to Maqusood Ahamed; maqusood@gmail.com

Received 16 July 2013; Revised 11 November 2013; Accepted 31 December 2013; Published 9 February 2014

Academic Editor: Do Kim

Copyright (C) 2014 Maqusood Ahamed et al. This is an open access article distributed under the Creative Commons Attribution License, which permits unrestricted use, distribution, and reproduction in any medium, provided the original work is properly cited.

\begin{abstract}
We studied the structural and antimicrobial properties of copper oxide nanoparticles (CuO NPs) synthesized by a very simple precipitation technique. Copper (II) acetate was used as a precursor and sodium hydroxide as a reducing agent. X-ray diffraction patter (XRD) pattern showed the crystalline nature of CuO NPs. Field emission scanning electron microscope (FESEM) and field emission transmission electron microscope (FETEM) demonstrated the morphology of CuO NPs. The average diameter of $\mathrm{CuO}$ NPs calculated by TEM and XRD was around $23 \mathrm{~nm}$. Energy dispersive X-ray spectroscopy (EDS) spectrum and XRD pattern suggested that prepared $\mathrm{CuO}$ NPs were highly pure. CuO NPs showed excellent antimicrobial activity against various bacterial strains (Escherichia coli, Pseudomonas aeruginosa, Klebsiella pneumonia, Enterococcus faecalis, Shigella flexneri, Salmonella typhimurium, Proteus vulgaris, and Staphylococcus aureus). Moreover, E. coli and E. faecalis exhibited the highest sensitivity to CuO NPs while K. pneumonia was the least sensitive. Possible mechanisms of antimicrobial activity of CuO NPs should be further investigated.
\end{abstract}

\section{Introduction}

Metal oxide nanoparticles (NPs) have been receiving considerable attention for their potential applications in optoelectronics, nanodevices, nanoelectronics, nanosensors, information storage, and catalysis. Among various metal oxide NPs, $\mathrm{CuO}$ has attracted particular attention because it is the simplest member of the family of copper compounds and shows a range of useful physical properties such as high temperature superconductivity, electron correlation effects, and spin dynamics $[1,2]$. $\mathrm{CuO}$ NPs are increasingly used in various applications such as in catalysis, batteries, gas sensors, heat transfer fluids, and solar energy [3]. $\mathrm{CuO}$ crystal structures possess a narrowband gap, giving useful photocatalytic and photovoltaic properties [4].
Microbial contamination of air, water, and soil due to different types of microorganisms creates problems in living conditions and is a serious issue in health care. Due to the spread of antibiotic resistant infections, interest in alternative antimicrobial agents, such as small antibiotics, cationic polymers, metal NPs, and antimicrobial peptides have been rising [5]. In this study, we reported synthesis, characterization, and antimicrobial activity of $\mathrm{CuO}$ NPs. CuO NPs were synthesized by a simple precipitation technique. Structural property of $\mathrm{CuO}$ NPs was examined by X-ray diffraction (XRD), field emission scanning electron microscopy (FESEM), and field emission transmission electron microscopy (FETEM) equipped with energy dispersive X-ray spectroscopy (EDS). Antimicrobial activity of $\mathrm{CuO}$ NPs was examined by a well disk diffusion assay and minimum inhibitory concentration (MIC) of $\mathrm{CuO}$ NPs against various bacterial strains. 


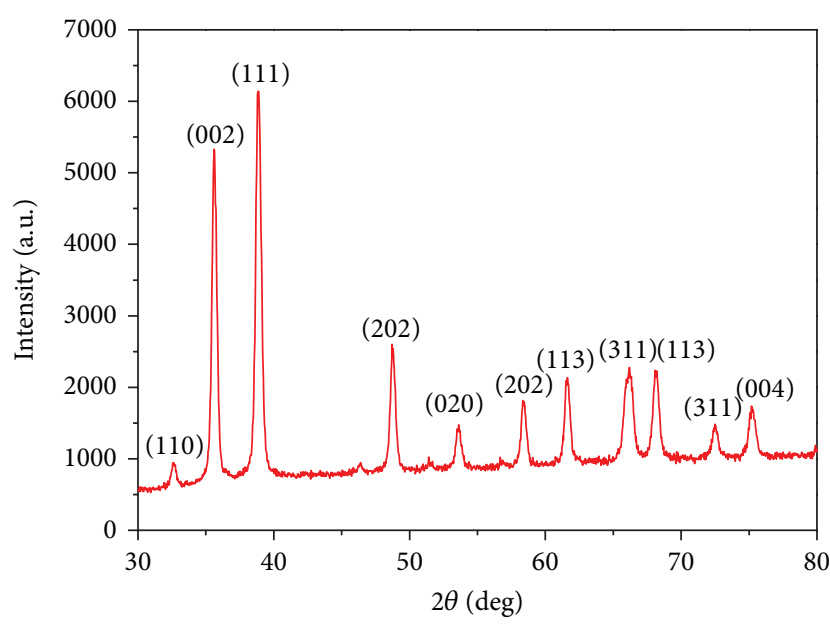

FIgURE 1: XRD pattern of CuO NPs.

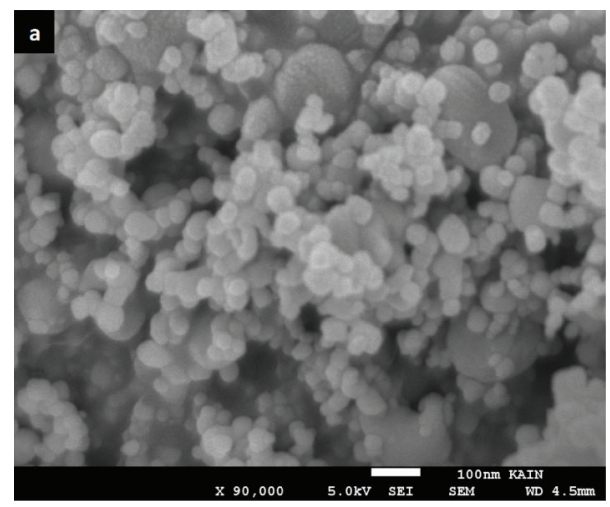

(a)

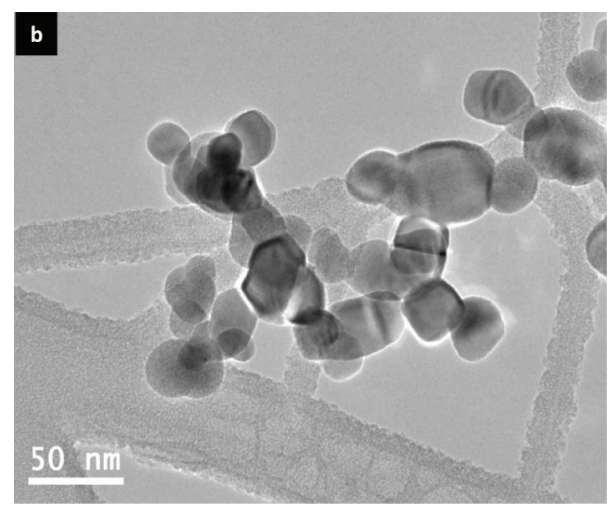

(b)

Figure 2: (a) FESEM image of CuO NPs and (b) FETEM image of $\mathrm{CuO}$ NPs.

\section{Materials and Methods}

2.1. Synthesis of $\mathrm{CuO}$ NPs. $\mathrm{CuO}$ NPs were synthesized by aqueous precipitation method using copper (II) acetate $\left.\left[\mathrm{Cu}\left(\mathrm{CH}_{3} \mathrm{COO}\right)_{2} \cdot \mathrm{H}_{2} \mathrm{O}\right)\right](98 \%$, Sigma-Aldrich $)$ as a precursor and sodium hydroxide $(\mathrm{NaOH})$ as a reducing agent. In brief, $0.2 \mathrm{M}$ copper (II) acetate solution $(600 \mathrm{~mL})$ and glacial acetic acid $\left(\mathrm{CH}_{3} \mathrm{COOH}\right)(2 \mathrm{~mL})$ were added into a roundbottomed flask and heated to boiling under magnetic stirring. Then, $30 \mathrm{~mL}$ of $6 \mathrm{M} \mathrm{NaOH}$ solution was poured into the flask. The colour of the solution turned from blue to black immediately, and a black suspension formed simultaneously. The reaction was carried out under stirring and boiling for $2.5 \mathrm{~h}$. The mixture was cooled to room temperature and centrifuged. Then, a wet $\mathrm{CuO}$ precipitate was obtained. The precipitates were filtered and washed with distilled water and absolute ethanol for several times. The resulting product was dried (at $60^{\circ} \mathrm{C}$ for $6 \mathrm{~h}$ ) to obtain the dry powder of $\mathrm{CuO}$ NPs. The yield of prepared $\mathrm{CuO}$ NPs was $52 \%$.

2.2. Characterization of $\mathrm{CuO}$ NPs. The crystalline nature of $\mathrm{CuO}$ NPs was carried out by XRD. The XRD pattern of $\mathrm{CuO}$ nanopowder was acquired at room temperature with the help of a PANalytical X'Pert X-ray diffractometer equipped with an Ni filtered using $\mathrm{Cu} \mathrm{K} \alpha(\lambda=1.54056 \AA)$ radiations as an X-ray source. Structural studies of $\mathrm{CuO}$ NPs were done by FESEM (JSM-7600F, JEOL Inc.) and FETEM (JEM-2100F, JEOL Inc.) at an accelerating voltage of $15 \mathrm{kV}$ and $200 \mathrm{kV}$, respectively. EDS was utilized to determine the elemental composition (purity) of prepared $\mathrm{CuO}$ NPs.

2.3. Antibacterial Activity of $\mathrm{CuO}$ NPs. Seven human gram negative bacteria Escherichia coli (ATCC 27853), Pseudomonas aeruginosa (ATCC 25922), Klebsiella pneumonia (ATCC 8308), Enterococcus faecalis (ATCC 29212), Shigella flexneri (ATCC 12022), Salmonella typhimurium (ATCC 14028), and Proteus vulgaris (ATCC 8427) along with one human gram positive bacterium Staphylococcus aureus (ATCC 25923) were maintained on nutrient agar slants that contained peptone $(5.0 \mathrm{~g})$, meat extract $(1.0 \mathrm{~g})$, yeast extract $(2.0 \mathrm{~g})$, sodium chloride $(5.0 \mathrm{~g})$, and agar $(15.0 \mathrm{~g})$ per liter of distilled water. Bacterial sensitivity to antibiotics or NPs is commonly tested using a well diffusion assay, utilizing antibiotics or NPs impregnated disks [6]. Prepared CuO NPs suspension was added into the wells. The samples were initially incubated for $15 \mathrm{~min}$ at $4^{\circ} \mathrm{C}$ (to allow diffusion) and later on at $37^{\circ} \mathrm{C}$ for $24 \mathrm{~h}$. Positive test results were scored when a zone of inhibition was observed around the well after the incubation period. The mean and standard deviation (SD) reported for each concentration and with each microbial strain were based on six replicates.

The minimum inhibitory concentration (MIC) was determined based on a broth microdilution method as described elsewhere [7]. Briefly, bacteria were cultured overnight at $37^{\circ} \mathrm{C}$ in Mueller-Hinton (MH) broth and adjusted to a final density of $10^{8} \mathrm{CFU} / \mathrm{mL}$ by $0.5 \mathrm{McF}$ arland standards. Then, in 96 -well plate we added $90 \mu \mathrm{L}$ of $\mathrm{MH}$ broth, $10 \mu \mathrm{L}$ of bacterial inoculum, and $10 \mu \mathrm{L}$ of $\mathrm{CuO}$ NPs with different concentrations. Further, 96-well plate was incubated at $37^{\circ} \mathrm{C}$ for $12 \mathrm{~h}$. After incubation, the bacterial growth was visually inspected and the lowest concentration of $\mathrm{CuO}$ at which no observable bacterial growth was taken as the MIC value. The experiments were carried out in six replicates. 


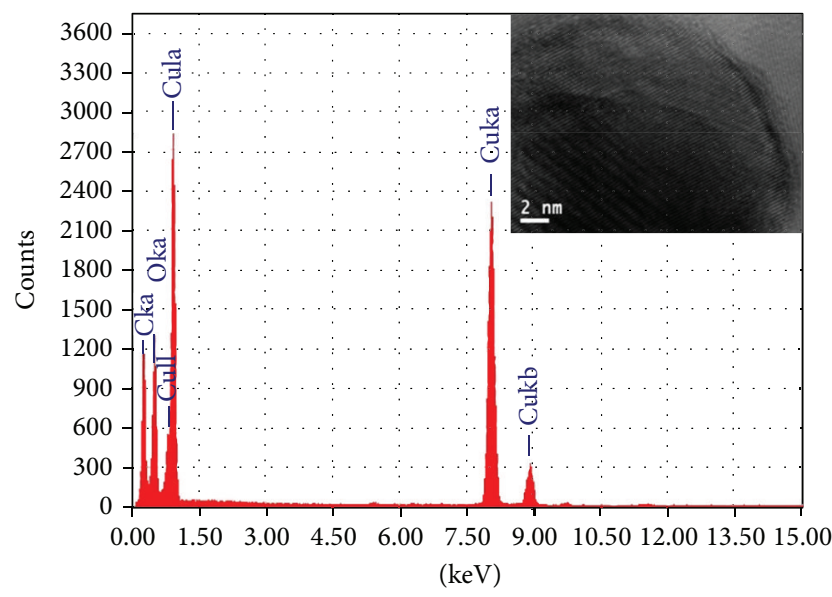

FIGURE 3: EDS profile of $\mathrm{CuO}$ NPs and inset shows high resolution TEM of the same.

2.4. Statistical Analysis. Antimicrobial data represented are mean \pm SD of three identical experiments made in six replicates. Statistical analysis conducted using the Prism software (GraphPad Software Inc.).

\section{Results and Discussion}

3.1. Structural Properties CuO NPs. Figure 1 shows the XRD pattern of CuO NPs. All the peaks of CuO NPs can be indexed to the monoclinic crystal system $\mathrm{CuO}(\mathrm{C} 2 / \mathrm{c}$ space group, JCPDS card no. 45-0937). No characteristic peaks of any impurities were detected, suggesting that high quality of $\mathrm{CuO}$ NPs was prepared. The crystallite size has been estimated from the XRD pattern using the Scherrer's equation [8]:

$$
d=\frac{K \lambda}{\beta \cos \theta},
$$

where $K=0.9$ is the shape factor, $\lambda$ is the $\mathrm{X}$-ray wavelength of $\mathrm{Cu} \mathrm{K} \alpha$ radiation (1.54 $\AA$ ), $\theta$ is the Bragg diffraction angle, and $\beta$ is the FWHM of the respective diffraction peak. The crystallite size corresponding to the highest peak observed in XRD was found to be $23.43 \mathrm{~nm}$. The presence of sharp structural peaks in XRD patterns and crystallite size less than $100 \mathrm{~nm}$ suggested the nanocrystalline nature of $\mathrm{CuO}$ NPs. Figures 2(a) and 2(b) show the typical SEM and TEM images of the $\mathrm{CuO}$ NPs, respectively. The average diameter of $\mathrm{CuO}$ NPs was calculated from measuring over 100 particles in random field of TEM view. The average TEM size of CuO NPs was around $23.17 \mathrm{~nm}$, supporting the XRD results. The EDS spectrum of $\mathrm{CuO}$ NPs is given in Figure 3. The EDS results show that there are no other elemental impurities present in the prepared $\mathrm{CuO}$ NPs. High resolution TEM of $\mathrm{CuO}$ NPs also shows the crystalline nature (inset Figure 3).

3.2. Antimicrobial Activity of $\mathrm{CuO}$ NPs. Antimicrobial activity of $\mathrm{CuO}$ NPs was analyzed against various bacterial strains Escherichia coli, Pseudomonas aeruginosa, Klebsiella pneumonia, Enterococcus faecalis, Shigella flexneri, Salmonella typhimurium, Proteus vulgaris, and Staphylococcus aureus.

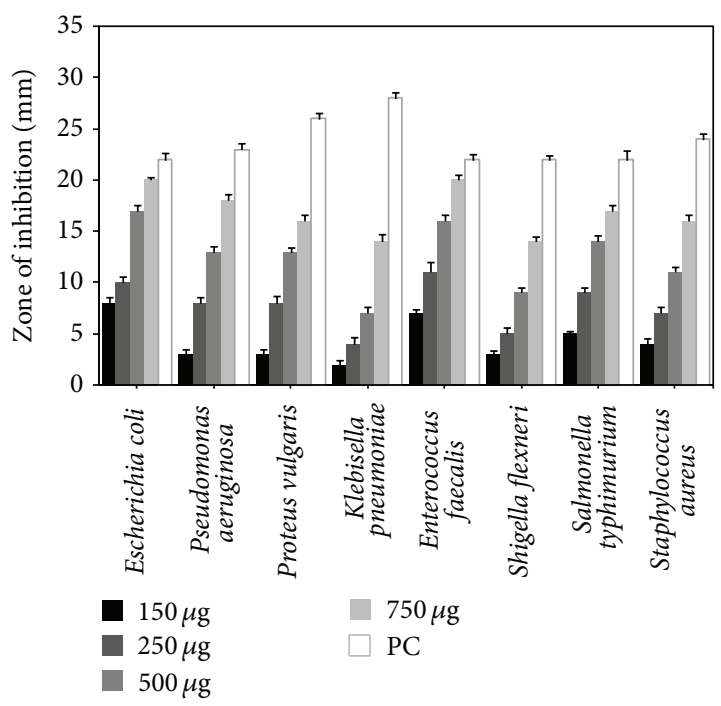

(a)

\begin{tabular}{cc}
\hline Organisms & MIC $(\mu \mathrm{g} / \mathrm{mL})$ \\
\hline Escherichia coli & 31.25 \\
\hline Pseudomonas aeruginosa & 125 \\
\hline Proteus vulgaris & 125 \\
\hline Klebsiella pneumonia & 250 \\
\hline Enterococcus faecalis & 31.25 \\
\hline Shigella flexneri & 125 \\
\hline Salmonella typhimurium & 62.5 \\
\hline Staphylococcus aureus & 62.5 \\
\hline
\end{tabular}

(b)

Figure 4: (a) Well diffusion assay of $\mathrm{CuO}$ NPs against various bacterial strains and (b) MIC of $\mathrm{CuO}$ NPs for various bacterial strains. PC: positive control (streptomycin $150 \mu \mathrm{g} / \mathrm{mL}$ ).

Figure 4(a) represents the antibacterial activity of $\mathrm{CuO}$ NPs for various bacteria in a well diffusion assay. Results showed that $\mathrm{CuO}$ NPs demonstrated excellent antimicrobial activity against a range of bacteria. The diameter of inhibition zone reflects magnitude of susceptibility of microbes. The strains susceptible to $\mathrm{CuO}$ NPs exhibited larger zone of inhibition, whereas resistant strains exhibit smaller zone of inhibition. According to zone of inhibition E. coli and $E$. faecalis exhibited the highest sensitivity toward CuO NPs while $K$. pneumonia showed the least sensitivity among the tested microbes. Figure 4(b) shows the MIC value of $\mathrm{CuO}$ NPs. The MIC is defined as the lowest concentration of NPs that inhibits the growth of a microorganism. Similar to well diffusion assay, the lowest MIC $(31.25 \mu \mathrm{g} / \mathrm{mL})$ was for $E$. coli and E. faecalis while the highest MIC $(250 \mu \mathrm{g} / \mathrm{mL})$ was for 
K. pneumonia. The MIC values found in this study were slightly higher than those reported by Vellora et al. [9]. This could be due smaller size $(20 \mathrm{~nm})$ of $\mathrm{CuO}$ NPs used by Azam et al. than those of the present study $(23 \mathrm{~nm})$. Azam et al. [10] also reported the antimicrobial activity of $\mathrm{CuO}$ NPs prepared by green method. The MIC of E. coli and S. aureus was $103 \mu \mathrm{g} / \mathrm{mL}$ and $120 \mu \mathrm{g} / \mathrm{mL}$, respectively.

\section{Conclusion}

Highly pure $\mathrm{CuO}$ NPs was prepared by a simple precipitation method. XRD spectrum revealed that $\mathrm{CuO}$ NPs were monoclinic crystals with space group C2/c. FESEM and FETEM showed the morphology of CuO NPs. The average TEM diameter of $\mathrm{CuO}$ NPs was around $23 \mathrm{~nm}$ that agreed fairly well with XRD data. CuO NPs showed excellent antimicrobial activity against eight bacterial strains. Consequently, $\mathrm{CuO}$ NPs have potential for external uses as antibacterial agents in surface coatings on various substrates to prevent microorganisms from attaching, colonizing, spreading, and forming biofilms in indwelling medical devices. This study suggests that mechanisms of antimicrobial response of $\mathrm{CuO}$ NPs in different species of bacterial should be further investigated.

\section{Conflict of Interests}

We declare that we have no conflict of interests.

\section{Acknowledgment}

The authors extend their appreciation to the Deanship of Scientific Research at King Saud University for funding this work through research group no. RGP-VPP-308.

\section{References}

[1] F. Marabelli, G. B. Parravicini, and F. Salghetti-Drioli, "Optical gap of CuO," Physical Review B, vol. 52, no. 3, pp. 1433-1436, 1995.

[2] A. El-Trass, H. Elshamy, I. El-Mehasseb, and M. El-Kemary, "CuO nanoparticles: synthesis, characterization, optical properties and interaction with amino acids," Applied Surface Science, vol. 258, no. 7, pp. 2997-3001, 2012.

[3] G. Filipic and U. Cvelbar, "Copper oxide nanowires: a review of growth," Nanotechnology, vol. 23, no. 19, Article ID 194001, 2012.

[4] J. Li, F. Sun, K. Gu, T. Wu, W. Zhai, and W. Li, "Preparation of spindly $\mathrm{CuO}$ micro-particles for photodegradation of dye pollutants under a halogen tungsten lamp," Applied Catalysis A, vol. 406, no. 1-2, pp. 51-58, 2011.

[5] G. Ren, D. Hu, E. W. C. Cheng, M. A. Vargas-Reus, P. Reip, and R. P. Allaker, "Characterisation of copper oxide nanoparticles for antimicrobial applications," International Journal of Antimicrobial Agents, vol. 33, no. 6, pp. 587-590, 2009.

[6] C. L. Case and T. R. Johnson, Laboratory Experiments in Microbiology, Benjamin Cummings, California, Calif, USA, 1984.

[7] F. A. Al-Bayati, "Synergistic antibacterial activity between Thymus vulgaris and Pimpinella anisum essential oils and methanol extracts," Journal of Ethnopharmacology, vol. 116, no. 3, pp. 403406, 2008.
[8] A. L. Patterson, "The scherrer formula for X-ray particle size determination," Physical Review, vol. 56, no. 10, pp. 978-982, 1939.

[9] V. Vellora, T. Padil, and M. Cernik, "Green synthesis of copper oxide nanoparticles using gum karaya as a biotemplate and their antibacterial application," International Journal of Nanomedicine, vol. 8, no. 1, pp. 889-898, 2013.

[10] A. Azam, A. S. Ahmed, M. Oves, M. S. Khan, and A. Memic, "Size-dependent antimicrobial properties of $\mathrm{CuO}$ nanoparticles against Gram-positive and -negative bacterial strains," International Journal of Nanomedicine, vol. 7, pp. 3527-3535, 2012. 

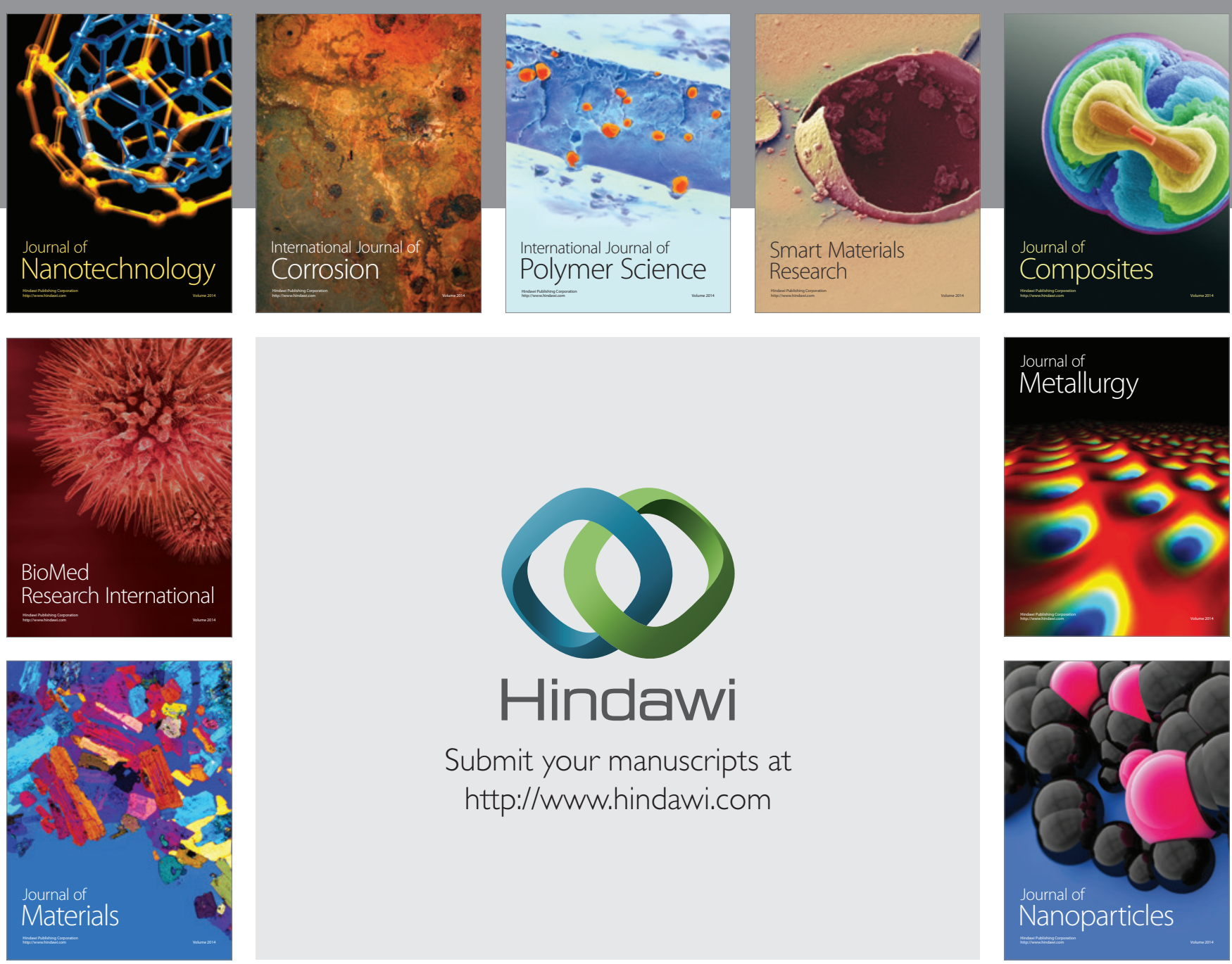

Submit your manuscripts at http://www.hindawi.com
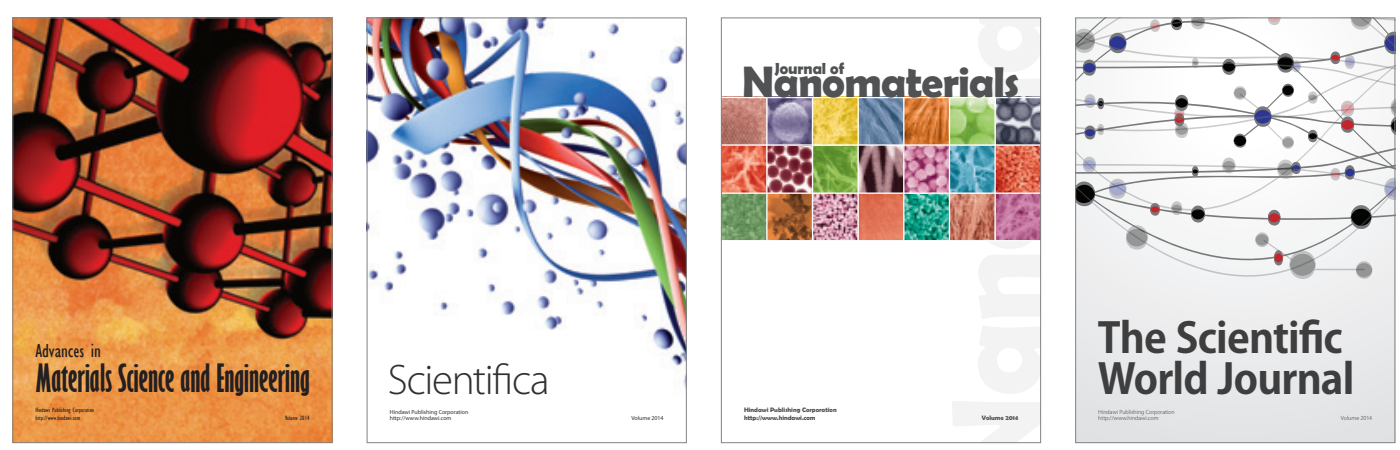

\section{The Scientific World Journal}
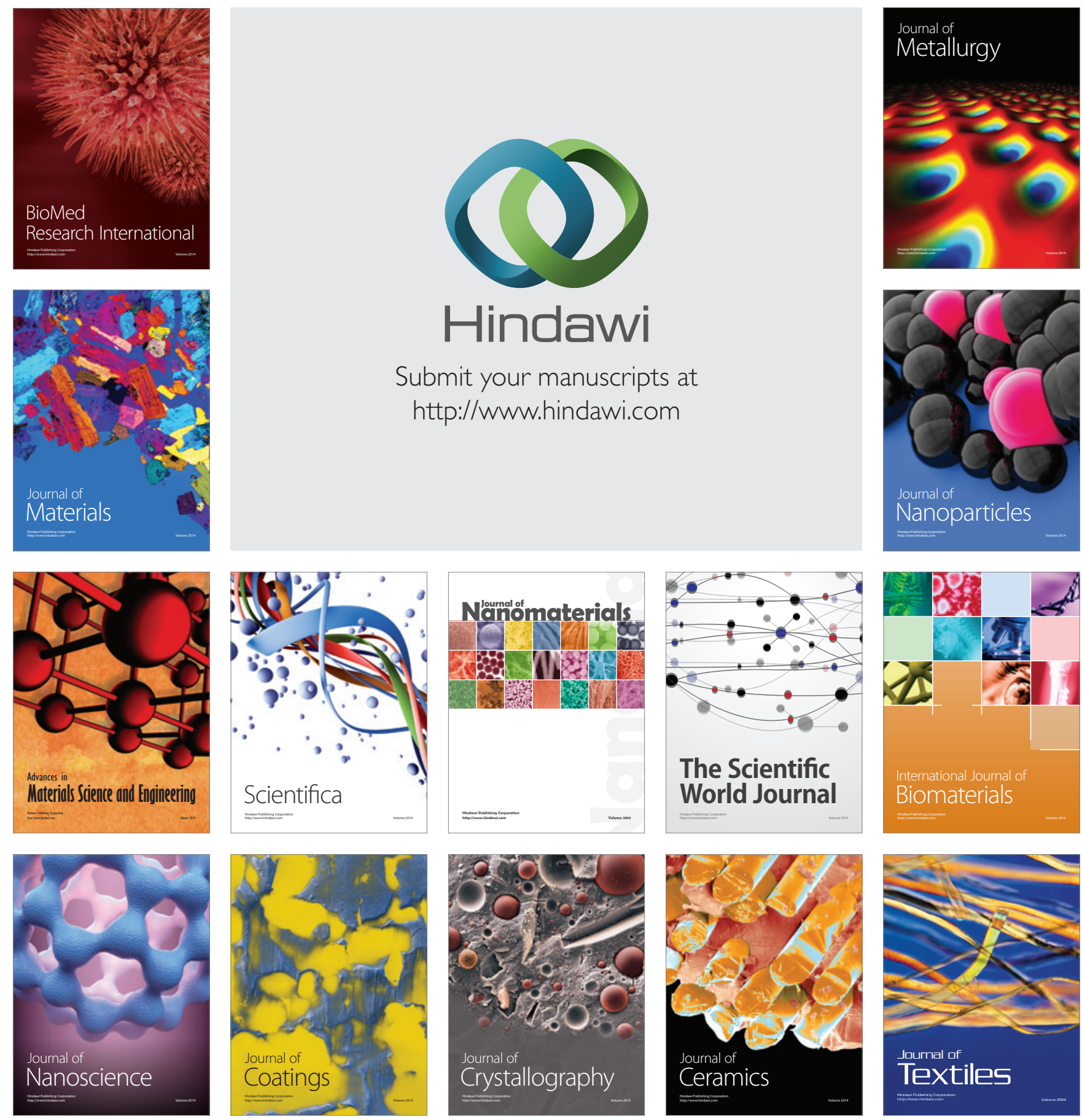